\title{
Effects of Home-Based Breathing Exercises in Subjects With COPD
}

\author{
Yufan Lu, Peijun Li, Ning Li, Zhengrong Wang, Jian Li, Xiaodan Liu, \\ and Weibing $\mathrm{Wu}$
}

\begin{abstract}
BACKGROUND: We sought to investigate the effects of home-based breathing exercises on pulmonary function, respiratory muscle strength, exercise capacity, dyspnea, and health-related quality of life in patients with COPD. METHODS: All randomized, controlled trials involving the use of home-based breathing exercises as an intervention in patients with COPD were searched on PubMed, Embase, Web of Science, EBSCO, CNKI, and Wangfang Data databases from January 1, 2008, to December 31, 2018. Two researchers independently extracted data and assessed the quality of the literature that met the inclusion criteria. RESULTS: A total of 13 studies were included, with a total of 998 subjects. The intervention methods consisted of diaphragmatic breathing, yoga breathing, breathing gymnastics, and singing. Meta-analysis showed that, compared with the control group, home-based breathing exercises had significant effects on the percent of predicted $\mathrm{FEV}_{1}$ (mean difference $=3.26,95 \% \mathrm{CI} 0.52-5.99, P=.02), \mathrm{FEV}_{1} / \mathrm{FVC}$ (mean difference $=\mathbf{2 . 8 4}, 95 \% \mathrm{CI}$ 1.04-4.64, $P=.002$ ), maximum inspiratory pressures (mean difference $=20.20,95 \%$ CI 11.78 $28.61, P<.001$ ), maximum expiratory pressures (mean difference $=26.35,95 \%$ CI 12.64 to 40.06 , $P<.001$ ), 6-min walk distance (mean difference $=36.97,95 \%$ CI $25.06-48.89, P<.001$ ), the modified Medical Research Council dyspnea scale (mean difference $=-0.80,95 \% \mathrm{CI}-1.06$ to -0.55 , $P<.001$ ), and the St George Respiratory Questionnaire (mean difference $=-8.62,95 \% \mathrm{CI}-13.09$ to $-4.16, P<.001)$. CONCLUSIONS: As an alternative method of home-based pulmonary rehabilitation program, breathing exercises can improve pulmonary function, respiratory muscle strength, exercise capacity, dyspnea, health-related quality of life in patients with COPD. Key words: chronic obstructive pulmonary disease; breathing exercises; pulmonary function; exercise capacity; quality of life. [Respir Care 2020;65(3):377-387. (C) 2020 Daedalus Enterprises]
\end{abstract}

\section{Introduction}

COPD is a progressive inflammatory lung condition that seriously affects human health and is the third lead-

\footnotetext{
Ms Lu, Ms P. Li, Ms N. Li, Mr Wang, Mr J. Li, and Mr Wu are affiliated with the Department of Sports Medicine, Shanghai University of Sport, Shanghai, China. Ms Liu is affiliated with the School of Rehabilitation Science, Shanghai University of Traditional Chinese Medicine, and the Institute of Rehabilitation Medicine, Shanghai Academy of Traditional Chinese Medicine, Shanghai, China.
}

This work was funded by the General Administration of Sport of China (No. 2017B021), the "Qi Kang" young innovative talents project of School of Rehabilitation Medicine in Shanghai University of Traditional Chinese Medicine, the Science and Technology Commission of Shanghai Municipality (No. 18DZ1200600), and the Shanghai University of Sport "High-level International Talent Training Program". ing cause of death worldwide. ${ }^{1}$ The global prevalence of COPD has reached $20.9 \% .^{2}$ Its high mortality and prevalence have made COPD a serious public health problem, with a heavy social and economic burden. ${ }^{3}$ COPD not only affects the lungs, causing dyspnea and reduced pulmonary function, but it is also accompanied by multiple and systemic comorbidities, which leads to respiratory muscle dysfunction that further impairs exercise capacity. ${ }^{4}$ Pulmonary rehabilitation, as a comprehensive intervention program, can effectively enhance the phys-

\footnotetext{
Correspondence: Xiaodan Liu PhD, School of Rehabilitation Science, Shanghai University of Traditional Chinese Medicine, Shanghai 201203, China. E-mail: hzhp403@126.com.
}

DOI: $10.4187 /$ respcare.07121 
ical and psychological condition of patients with COPD. ${ }^{5}$ As a kind of low-intensity aerobic exercise, breathing exercises reduce hyperinflation by improving the strength and endurance of respiratory muscles and correcting abnormal chest and abdomen movement patterns. Consequently, pulmonary function, dyspnea, and exercise capacity are improved, along with health-related quality of life (HRQOL) in patients with COPD. ${ }^{6}$

Breathing exercises are a direct training method for respiratory muscles, and they are highly targeted and less restricted by the environment. It is an effective home-based pulmonary rehabilitation method that can be practiced independently by patients with COPD. There are various types of breathing exercises, including diaphragmatic breathing, pursed-lips breathing, yoga breathing, breathing gymnastics, and singing. ${ }^{7}$ Borge et al ${ }^{8}$ compared breathing exercises with respiratory muscle training using threshold devices and reported that breathing exercises can manage and control breathing during exertion. However, respiratory muscle training requires a training program based on respiratory muscle strengthening to improve dyspnea. Another study found that pursed-lips breathing is not only conducive to increasing patients' confidence in their ability to use the technique for long-term management of dyspnea, but it can also be used effectively at night. ${ }^{9}$ In addition, minute ventilation and breathing frequency during exercise could be effectively reduced through breathing exercises. ${ }^{10}$ Research has shown that yoga breathing can effectively improve respiratory muscle strength in subjects with COPD. ${ }^{11}$ Casey et al ${ }^{12}$ reported that breathing exercises can effectively alleviate patient dyspnea due to its effectiveness in improving respiratory muscle strength. Some researchers have confirmed that breathing exercises can also improve exercise capacity and HRQOL in patients with COPD and can be recommended as an effective training modality in pulmonary rehabilitation. ${ }^{13}$

However, the effectiveness of breathing exercises varies depending on design and type. Researchers report that diaphragmatic breathing may have different effects compared with pursed-lips breathing, in that the former aims to reduce work of breathing in patients with COPD and the latter aims to improve gas exchange. ${ }^{14-16}$ Moreover, breathing exercises using metronome-based acoustic feedback did not significantly improved exercise endurance or decrease the work of breathing for subjects with COPD compared with exercise training alone. ${ }^{17}$ Therefore, it is necessary to integrate the results of individual studies to clarify the impact of breathing exercises on subjects with COPD. The aim of this meta-analysis was to determine the effects of breathing exercises on pulmonary function, respiratory muscle strength, exercise capacity, dyspnea, and HRQOL in subjects with COPD.

\section{Methods}

\section{Search Strategy}

This systematic review was registered (PROSPERO registration number: CRD42019129458) and is reported in accordance with the Preferred Reporting Items for Systematic Reviews and Meta-Analyses (PRISMA) statement. ${ }^{18}$ To identify relevant manuscripts, the online databases of PubMed, Embase, Web of Science, Ebsco, China National Knowledge Infrastructure (CNKI), and WanFang Data were searched. The following search terms were used: ("chronic obstructive pulmonary disease" OR "COPD" OR "chronic air flow obstruction" OR "bronchitis chronic" OR "pulmonary emphysema") AND ("breathing exercises" OR "exercise of breathing" OR "breathing control exercises" OR "diaphragmatic breathing" OR "pursed-lips breathing" OR "yoga" OR "breathing gymnastics" OR "singing"). Medical Subject Headings (MeSH) terms and free-text key words were used. The search strategies were written according to the retrieval requirements of each database. Search filters were applied to limit publication time (January 1, 2008, to December 31, 2018), article type (randomized controlled trials), species (humans), and language (English/Chinese) in all database output. In addition, the reference lists of potentially relevant studies were screened to make the review of the articles as complete as possible.

\section{Inclusion Criteria}

We structured the criteria for study selection according to the principles of PICO (population, intervention, comparison, outcomes). Subjects had to be diagnosed with COPD confirmed by a pulmonologist or spirometry $\left(\mathrm{FEV}_{1} / \mathrm{FVC}<0.719\right)$ with no history of COPD exacerbation within the previous 6 weeks. There were no gender and age restrictions. We required that at least one type of home-based breathing exercises was used for intervention (ie, diaphragmatic breathing, pursed-lips breathing, yoga breathing, breathing gymnastics, or singing). We required that the home-based breathing exercises intervention was compared against a usual treatment. With regard to outcomes, studies were included if they measured lung function parameter (percent of predicted $\mathrm{FEV}_{1}$ and $\mathrm{FEV}_{1} / \mathrm{FVC}$ ), respiratory muscle strength (maximum inspiratory pressures $\left[\mathrm{P}_{\mathrm{Imax}}\right]$ and maximum expiratory pressures $\left.\left[\mathrm{P}_{\mathrm{Emax}}\right]\right)$, exercise capacity (6-min walk distance [6MWD]), dyspnea (modified Medical Research Council [mMRC] dyspnea scale), and HRQOL (St George Respiratory Questionnaire). Finally, studies were included only if the study design was a randomized controlled trial. 
Home-Based Breathing Exercises in COPD

Table 1. PEDro Criteria and Scores of the Included Randomized Controlled Trials

\begin{tabular}{|c|c|c|c|c|c|c|c|c|c|c|c|}
\hline Study & $\begin{array}{c}\text { Random } \\
\text { Allocation }\end{array}$ & $\begin{array}{c}\text { Concealed } \\
\text { location }\end{array}$ & $\begin{array}{l}\text { Baseline } \\
\text { Similar }\end{array}$ & $\begin{array}{l}\text { Blinding } \\
\text { (Subject) }\end{array}$ & $\begin{array}{l}\text { Blinding } \\
\text { (Therapist) }\end{array}$ & $\begin{array}{l}\text { Blinding } \\
\text { (Assessor) }\end{array}$ & $\begin{array}{l}\text { Measures for } \\
>85 \%\end{array}$ & $\begin{array}{l}\text { Intention- } \\
\text { to-Treat } \\
\text { Analysis }\end{array}$ & $\begin{array}{l}\text { Between-Group } \\
\text { Difference } \\
\text { Reported }\end{array}$ & $\begin{array}{l}\text { Point Estimate } \\
\text { and Variability } \\
\text { Reported }\end{array}$ & $\begin{array}{l}\text { Quality } \\
\text { Score } \\
(0-10)\end{array}$ \\
\hline Bonilha et $\mathrm{al}^{31}$ & $\mathrm{Y}$ & $\mathrm{N}$ & $\mathrm{Y}$ & $\mathrm{N}$ & $\mathrm{N}$ & $\mathrm{N}$ & $\mathrm{Y}$ & $\mathrm{N}$ & $\mathrm{Y}$ & $\mathrm{Y}$ & 5 \\
\hline Gu et $\mathrm{al}^{30}$ & $\mathrm{Y}$ & $\mathrm{N}$ & $\mathrm{Y}$ & $\mathrm{N}$ & $\mathrm{N}$ & $\mathrm{N}$ & $\mathrm{Y}$ & $\mathrm{N}$ & $\mathrm{Y}$ & $\mathrm{Y}$ & 5 \\
\hline Hu et $\mathrm{al}^{24}$ & $\mathrm{Y}$ & $\mathrm{N}$ & $\mathrm{Y}$ & $\mathrm{N}$ & $\mathrm{N}$ & $\mathrm{Y}$ & $\mathrm{Y}$ & $\mathrm{Y}$ & $\mathrm{Y}$ & $\mathrm{Y}$ & 7 \\
\hline Kaminsky et $\mathrm{al}^{21}$ & $\mathrm{Y}$ & $\mathrm{Y}$ & $\mathrm{Y}$ & $\mathrm{Y}$ & $\mathrm{Y}$ & $\mathrm{Y}$ & $\mathrm{Y}$ & $\mathrm{N}$ & $\mathrm{Y}$ & $\mathrm{Y}$ & 9 \\
\hline $\mathrm{Li}^{26}$ & $\mathrm{Y}$ & $\mathrm{N}$ & $\mathrm{Y}$ & $\mathrm{N}$ & $\mathrm{N}$ & $\mathrm{N}$ & $\mathrm{Y}$ & $\mathrm{Y}$ & $\mathrm{Y}$ & $\mathrm{Y}$ & 6 \\
\hline Lin et $\mathrm{al}^{27}$ & $\mathrm{~N}$ & $\mathrm{~N}$ & $\mathrm{Y}$ & $\mathrm{Y}$ & $\mathrm{Y}$ & $\mathrm{Y}$ & $\mathrm{Y}$ & $\mathrm{N}$ & $\mathrm{Y}$ & $\mathrm{Y}$ & 7 \\
\hline Lord et $\mathrm{al}^{29}$ & $\mathrm{Y}$ & $\mathrm{Y}$ & $\mathrm{Y}$ & $\mathrm{N}$ & $\mathrm{Y}$ & $\mathrm{Y}$ & $\mathrm{Y}$ & $\mathrm{N}$ & $\mathrm{Y}$ & $\mathrm{Y}$ & 8 \\
\hline Ranjita et al25 & $\mathrm{Y}$ & $\mathrm{Y}$ & $\mathrm{Y}$ & $\mathrm{N}$ & $\mathrm{Y}$ & $\mathrm{Y}$ & $\mathrm{Y}$ & $\mathrm{N}$ & $\mathrm{Y}$ & $\mathrm{Y}$ & 8 \\
\hline Tang et $\mathrm{al}^{23}$ & $\mathrm{Y}$ & $\mathrm{N}$ & $\mathrm{Y}$ & $\mathrm{N}$ & $\mathrm{N}$ & $\mathrm{N}$ & $\mathrm{Y}$ & $\mathrm{Y}$ & $\mathrm{Y}$ & $\mathrm{Y}$ & 6 \\
\hline $\mathrm{Xu}$ et $\mathrm{al}^{28}$ & $\mathrm{Y}$ & $\mathrm{N}$ & $\mathrm{Y}$ & $\mathrm{N}$ & $\mathrm{Y}$ & $\mathrm{N}$ & $\mathrm{Y}$ & $\mathrm{Y}$ & $\mathrm{Y}$ & $\mathrm{Y}$ & 7 \\
\hline Yamaguti et al ${ }^{15}$ & $\mathrm{Y}$ & $\mathrm{N}$ & $\mathrm{Y}$ & $\mathrm{N}$ & $\mathrm{N}$ & $\mathrm{Y}$ & $\mathrm{Y}$ & $\mathrm{Y}$ & $\mathrm{Y}$ & $\mathrm{Y}$ & 7 \\
\hline Zhang et $\mathrm{al}^{32}$ & $\mathrm{Y}$ & $\mathrm{N}$ & $\mathrm{Y}$ & $\mathrm{N}$ & $\mathrm{N}$ & $\mathrm{N}$ & $\mathrm{Y}$ & $\mathrm{N}$ & $\mathrm{Y}$ & $\mathrm{Y}$ & 5 \\
\hline Zhang et al ${ }^{22}$ & $\mathrm{Y}$ & $\mathrm{Y}$ & $\mathrm{Y}$ & $\mathrm{N}$ & $\mathrm{N}$ & $\mathrm{N}$ & $\mathrm{Y}$ & $\mathrm{Y}$ & $\mathrm{Y}$ & $\mathrm{Y}$ & 7 \\
\hline
\end{tabular}

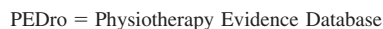

\section{Exclusion Criteria}

Trials were excluded if participants had other organic lesions or were in-patients; if other modes of exercise besides home-based breathing exercises were applied as the intervention; if the articles were case-control trials, cohort trials, crossover trials, cross-sectional studies, expert opinions, literature reviews, or letters; and if articles were not available in English or in Chinese.

\section{Study Collection and Data Collection}

Two reviewers independently screened the title and abstract of each study from the search strategy to rule out irrelevant studies. According to the abstract review, full articles were requested for comprehensive review. When details were missing from the abstracts, full articles were retrieved and checked for eligibility. Discrepancies were resolved through discussions with the third investigator. Two reviewers independently extracted the characteristics of the subjects (ie, sample size and participants' demographic characteristics), home-based breathing exercises interventions (ie, method, frequency, and intensity), and effects using a standardized form.

\section{Quality Assessment}

Each included study was scored to rate the methodological quality of study by the Physiotherapy Evidence Database (PEDro) scale. ${ }^{20}$ The PEDro scale contains 11 evaluation items, scored from the aspect of external authenticity, internal authenticity, and statistical information, with a total score of 10 points (Table 1). The 11 criteria of the PEDro scale were rated as "yes" (criteria were met and scored 1) or rated as "no" (criteria were not met and scored 0 ). Review quality was classified according to the PEDro scale score: 9-10 was considered high-quality literature, 6-8 was considered generally high-quality literature, 4-5 was considered medium-quality literature, and $<4$ was considered low-quality literature. Two investigators conducted quality assessments independently, and disagreements were resolved by seeking third-party opinions.

\section{Statistical Analysis}

Data were statistically analyzed using the Cochrane Collaboration software (RevMan 5.3). For each outcome, we tested the heterogeneity of results across studies using the chi-square test and the Higgins $I^{2}$ test. A fixed-effects model was used when $P \geq .10$ and $I^{2}<50 \%$, which was considered low heterogeneity. Otherwise, a random-effects model was conducted in the meta-analysis and the results were carefully interpreted. Weighted mean differences and 95\% CIs were used to pool data in continuous variables. For all results, a 2 -sided $P$ value of $\leq .05$ was considered to indicate a statistically significant difference.

\section{Results}

\section{Literature Search and Results}

According to the search strategy, a total of 6,733 potentially relevant studies were identified by searching from each database. After the 1,858 duplicates were removed, the titles and abstracts of 4,875 articles were screened, and 4,811 studies were excluded based on the exclusion criteria, such as inappropriate interventions, other interventions, and other study designs. Of the remaining 64 studies, 51 were excluded after full-text review, mainly because of the training forms used in intervention. Finally, 13 studies met the inclusion 


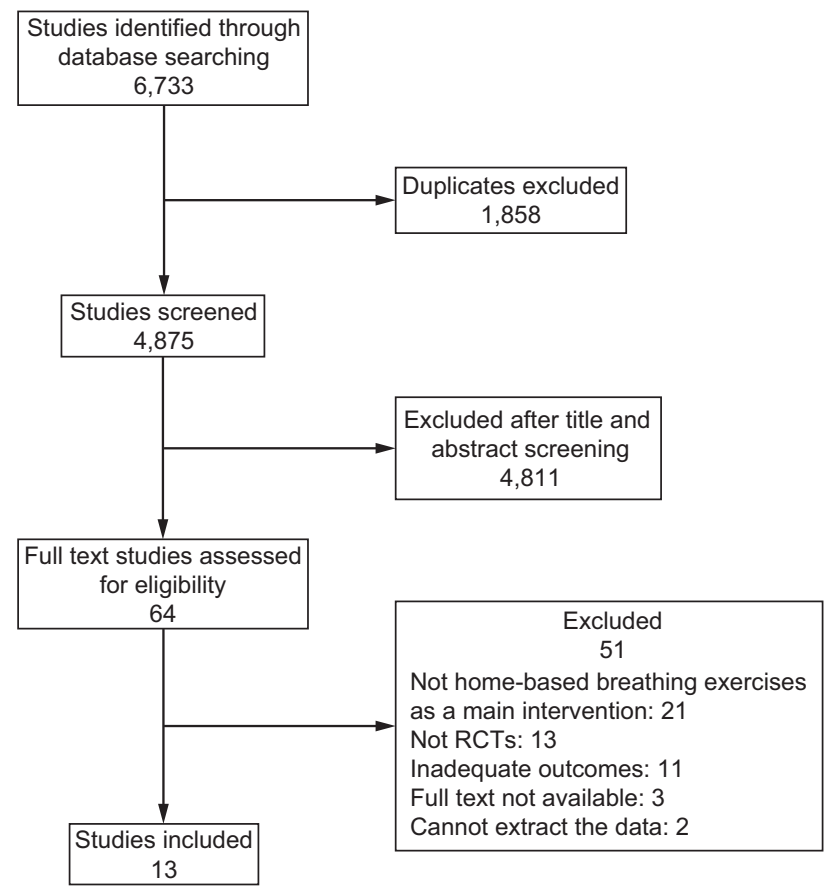

Fig. 1. Flow chart. RCT $=$ randomized controlled trial.

criteria and were included in the meta-analysis. The process of inclusion is shown in Figure 1.

\section{Characteristics of the Selected Studies}

A total of 998 subjects participated in the 13 randomized controlled trials included in our meta-analysis. Most of the included subjects had moderate or severe COPD. Considering all studies together, the subjects were predominantly male. The 13 studies involved 5 interventions: diaphragmatic breathing (1 study), pursed-lips breathing (1 study), yoga breathing (2 studies), breathing gymnastics (5 studies of traditional Chinese exercises combined with breathing and 2 of novel combined breathing exercises), and singing (2 studies). Session duration ranged from 10-60 min, with application frequency varying from once per day, 3 times per week to 3 times per day, 7 times per week. Program duration in the studies ranged from a minimum of 4 weeks to a maximum of 12 months. Characteristics of the 13 included studies are shown in Table 2.

\section{Quality of the Selected Literatures}

The detailed results of the quality assessment for the selected studies are shown in Table 1. One trial ${ }^{21}$ was evaluated as high-quality literature, 9 trials ${ }^{15,22-29}$ were generally highquality literature, and 3 trials $^{30-32}$ were of moderate quality. All studies reported that allocation was random. Six studies mentioned blinding the assessor collecting data. Eight studies used random assignment without reporting on allocation concealment, and 4 studies used computer-generated random numbers, applied consistently. One study was randomly assigned by coin toss with no report whether the allocation was hidden. Several authors reported difficulty in blinding, considering the type of therapy, thus only 2 studies were doubleblind, while 3 were single-blind. One study was performed for intention-to-treat analysis. Research protocols were available for all studies, and pre-declared outcomes were reported; there were no significant other biases.

\section{Outcomes}

Pulmonary Function. Ten studies investigated the effects of home-based breathing exercises on pulmonary function in subjects with COPD. There were 2 main outcome indices, including the percent of predicted $\mathrm{FEV}_{1}$ and $\mathrm{FEV}_{1} /$ FVC. Seven studies evaluated the effect of respiratory training on percent of predicted $\mathrm{FEV}_{1}$, and a fixed-effects model was used for meta-analysis due to decreased heterogeneity $\left(P=.48, I^{2}=0 \%\right)$. The results showed that home-based breathing exercises effectively improved the percent of predicted $\mathrm{FEV}_{1}$ in subjects with COPD (mean difference $=3.26,95 \%$ CI $0.52-5.99, P=.02$ ) (Fig. 2). Seven studies evaluated the effect of respiratory training on $\mathrm{FEV}_{1} / \mathrm{FVC}$, and a fixed-effects model was used for meta-analysis due to decreased heterogeneity $(P=.65$, $\left.I^{2}=0 \%\right)$. The overall analysis showed significant improvement in $\mathrm{FEV}_{1} / \mathrm{FVC}$ after home-based breathing exercises (mean difference $=2.84,95 \%$ CI 1.04-4.64, $P=.002$ ) (Fig. 2).

Expiratory Muscle Strength. The $\mathrm{P}_{\operatorname{Imax}}$ and $\mathrm{P}_{\mathrm{Emax}}$ were measured in 3 studies (Fig. 3). With less heterogeneity $\left(P=.96, I^{2}=0 \%\right)$, a fixed-effects model was used for meta-analysis. The analysis indicated that there were effective increases in $\mathrm{P}_{\text {Imax }}$ (mean difference $=20.20,95 \% \mathrm{CI}$ 11.78-28.61, $P<.001$ ) and $\mathrm{P}_{\text {Emax }}$ (mean difference $=26.35,95 \%$ CI 12.64-40.06, $P<.001$ ).

Exercise Capacity. Of the 13 trials, 9 studies assessed exercise capacity using the $6 \mathrm{MWD}$. When pooled in the meta-analysis, results showed a small heterogeneity $\left(P=.30, I^{2}=16 \%\right)$ and that the home-based breathing exercises led to significant improvements in the 6MWD (mean difference $=36.97,95 \%$ CI 25.06-48.89, $P<.001)$ (Fig. 4).

Dyspnea. The mMRC score was used to evaluate dyspnea. A pooled effect size from data of 5 studies with low heterogeneous $\left(P=.22, I^{2}=30 \%\right)$ indicated that homebased breathing exercises decreased mMRC scores of subjects with COPD $($ mean difference $=-0.80,95 \% \mathrm{CI}-1.06$ to $-0.55, P<.001$ ) (Fig. 5). 
Table 2. Characteristics of Included Studies

\begin{tabular}{|c|c|c|c|c|c|c|}
\hline Study & Group & $\begin{array}{l}\text { Sample Size } \\
(\% \text { male })\end{array}$ & Age, y & $\begin{array}{l}\text { GOLD } \\
\text { Stage }\end{array}$ & Intervention & Outcome \\
\hline \multirow[t]{2}{*}{ Bonilha et $\mathrm{al}^{31}$} & EG & $15(80)$ & $69.8 \pm 7.4$ & II, III & $\begin{array}{l}\text { Singing class (As a group: } 60 \mathrm{~min}, 1 / \mathrm{wk} \\
24 \mathrm{wk}+\text { At home: } 30 \mathrm{~min} \\
\text { 2/wk, } 24 \mathrm{wk} \text { ) }\end{array}$ & \multirow[t]{2}{*}{$\begin{array}{l}\mathrm{FEV}_{1} / \mathrm{FVC} ; \mathrm{P}_{\text {Imax }} \\
\quad \mathrm{P}_{\text {Emax }} ; \mathrm{SGRQ}\end{array}$} \\
\hline & CG & $15(80)$ & $73.6 \pm 7.5$ & II, III & $\begin{array}{l}\text { Handcraft work (As a group: } 60 \mathrm{~min}, \\
\text { 1/wk, } 24 \mathrm{wk}+\text { At home: } 30 \mathrm{~min}, 2 / \\
\text { wk, } 24 \mathrm{wk} \text { ) }\end{array}$ & \\
\hline \multirow[t]{2}{*}{$\mathrm{Gu}$ et $\mathrm{al}^{30}$} & EG & $22(95)$ & $65.18 \pm 6.25$ & II, III & $\begin{array}{l}\text { Novel breathing training ( } 15 \mathrm{~min}, 3 / \mathrm{d} \text {, } \\
8 \mathrm{wk} \text { ) }\end{array}$ & \multirow{2}{*}{$\begin{array}{l}\mathrm{FEV}_{1}(\text { pred } \%) ; \mathrm{P}_{\text {Imax }}, \\
\mathrm{P}_{\text {Emax }} ; 6 \mathrm{MWD} ; \\
\text { SGRQ, mMRC }\end{array}$} \\
\hline & CG & $20(95)$ & $67.55 \pm 7.50$ & II, III & Drug therapy & \\
\hline \multirow[t]{2}{*}{$\mathrm{Hu}$ et $\mathrm{al}^{24}$} & EG & 30 & & II, III & $\begin{array}{l}\text { Traditional Chinese medicine respiratory } \\
\text { guidance and rehabilitation technology } \\
(3 / \mathrm{d}, 5 \mathrm{~d} / \mathrm{wk}, 12 \mathrm{wk})\end{array}$ & \multirow[t]{2}{*}{$\mathrm{FEV}_{1}(\operatorname{pred} \%)$} \\
\hline & CG & 30 & & II, III & Health education & \\
\hline \multirow[t]{2}{*}{ Kaminsky et $\mathrm{al}^{21}$} & EG & $21(33)$ & $68 \pm 7$ & II-IV & Dirgha breath (60 min/d, $12 \mathrm{wk})$ & \multirow{2}{*}{$\begin{array}{l}\mathrm{FEV}_{1}(\text { pred } \%) \\
\text { 6MWD; SGRQ, } \\
\text { mMRC }\end{array}$} \\
\hline & CG & $22(45)$ & $68 \pm 9$ & II-IV & Usual care & \\
\hline \multirow[t]{2}{*}{$\mathrm{Li}^{26}$} & EG & 36 & & III, IV & Respiratory function training ( $2 / \mathrm{d}, 4 \mathrm{wk})$ & \multirow[t]{2}{*}{$\mathrm{FEV}_{1} / \mathrm{FVC} ; \mathrm{mMRC}$} \\
\hline & CG & 36 & & III, IV & Drug therapy & \\
\hline \multirow[t]{2}{*}{ Lin et $\mathrm{al}^{27}$} & EG & $20(75)$ & $67.95 \pm 12.36$ & II-IV & Respiratory training ( $30 \mathrm{~min}, 2 / \mathrm{d}, 12 \mathrm{wk}$ ) & \multirow{2}{*}{$\begin{array}{l}\mathrm{FEV}_{1}(\%), \mathrm{FEV}_{1} / \\
\text { FVC; 6MWD; } \\
\text { SGRQ }\end{array}$} \\
\hline & CG & $20(90)$ & $69.45 \pm 8.60$ & II-IV & $\begin{array}{l}\text { Routine health education }(30 \mathrm{~min}, 2 / \mathrm{d} \text {, } \\
12 \mathrm{wk})\end{array}$ & \\
\hline \multirow[t]{2}{*}{ Lord et $\mathrm{al}^{29}$} & EG & 15 & $66.6 \pm 9.3$ & & Singing workshops (60 min, 2/wk, $6 \mathrm{wk}$ ) & \multirow[t]{2}{*}{ SGRQ } \\
\hline & CG & 13 & $68.1 \pm 6.8$ & & Usual care (30 min, 2/wk, $12 \mathrm{wk})$ & \\
\hline \multirow[t]{2}{*}{ Ranjita et al ${ }^{25}$} & EG & $36(100)$ & $53.69 \pm 5.66$ & II, III & $\begin{array}{l}\text { Integrated approach of yoga therapy } \\
\quad(90 \mathrm{~min}, 6 / \mathrm{wk}, 12 \mathrm{wk})\end{array}$ & \multirow[t]{2}{*}{ 6MWD } \\
\hline & CG & $36(100)$ & $54.41 \pm 5.40$ & II, III & Usual care & \\
\hline \multirow[t]{2}{*}{ Tang et $\mathrm{al}^{23}$} & EG & $20(60)$ & $72.5 \pm 4.4$ & III, IV & $\begin{array}{l}\text { Novel breathing training }(15 \mathrm{~min}, 3 / \mathrm{d} \text {, } \\
8 \mathrm{wk})\end{array}$ & \multirow{2}{*}{$\begin{array}{l}\mathrm{FEV}_{1} / \mathrm{FVC} ; \mathrm{P}_{\text {Imax }} \\
\mathrm{P}_{\text {Emax }} ; 6 \mathrm{MWD} \\
\text { SGRQ, mMRC }\end{array}$} \\
\hline & CG & $20(60)$ & $72.1 \pm 4.2$ & III, IV & Drug therapy & \\
\hline \multirow[t]{2}{*}{$\mathrm{Xu}$ et $\mathrm{a}^{28}$} & EG & $20(50)$ & $56.83 \pm 7.93$ & I, II & $\begin{array}{l}\text { Integrative respiratory rehabilitation } \\
\text { therapy }(2 / \mathrm{d}, 48 \mathrm{wk})\end{array}$ & \multirow[t]{2}{*}{ 6MWD } \\
\hline & CG & $20(55)$ & $57.51 \pm 7.23$ & I, II & Drug therapy & \\
\hline \multirow[t]{2}{*}{ Yamaguti et al ${ }^{15}$} & EG & $15(73)$ & 66.4 & II-IV & $\begin{array}{l}\text { Diaphragmatic breathing training } \\
\text { program ( } 45 \mathrm{~min}, 3 / \mathrm{wk}, 4 \mathrm{wk})\end{array}$ & \multirow{2}{*}{$\begin{array}{l}\mathrm{FEV}_{1}(\operatorname{pred} \%) \\
\mathrm{FEV}_{1} / \mathrm{FVC} \\
\text { 6MWD; SGRQ, } \\
\text { mMRC }\end{array}$} \\
\hline & CG & $15(73)$ & 66.5 & II-IV & Usual care & \\
\hline \multirow[t]{2}{*}{ Zhang et $\mathrm{al}^{32}$} & EG & $20(85)$ & $68.85 \pm 3.92$ & III, IV & $\begin{array}{l}\text { Pulmonary rehabilitation with respiratory } \\
\text { physiology }(15 \mathrm{~min}, 3 / \mathrm{d}, 8 \mathrm{wk})\end{array}$ & \multirow{2}{*}{$\begin{array}{l}\mathrm{FEV}_{1}(\text { pred } \%), \\
\mathrm{FEV}_{1} / \mathrm{FVC} ; \mathrm{P}_{\text {Emax }}, \\
\mathrm{P}_{\text {Imax }} ; 6 \mathrm{MWD} ; \\
\text { mMRC }\end{array}$} \\
\hline & CG & $20(90)$ & $69.90 \pm 2.07$ & III, IV & No pulmonary rehabilitation & \\
\hline \multirow[t]{2}{*}{ Zhang et al 22} & EG & $232(66)$ & $63.38 \pm 9.70$ & II-IV & Pulmonary daoyin (10/wk, 12 wk) & \multirow[t]{2}{*}{ 6MWD } \\
\hline & $\mathrm{CG}$ & $229(64)$ & $63.44 \pm 11.00$ & II-IV & Drug therapy & \\
\hline \multicolumn{7}{|c|}{$\begin{array}{l}\text { Data are presented as } n(\%) \text { or mean } \pm \text { SD. } \\
\text { GOLD = Global Initiative for Chronic Obstructive Lung Disease } \\
\text { EG }=\text { experimental group } \\
\mathrm{CG}=\text { control group } \\
\mathrm{P}_{\text {Imax }}=\text { maximum inspiratory pressure } \\
\mathrm{P}_{\text {Emax }}=\text { maximum expiratory pressure } \\
6 \mathrm{MWD}=6 \text {-min walk distance } \\
\text { mMRC }=\text { modified Medical Research Council dyspnea scale } \\
\text { SGRQ }=\text { St. George's Respiratory Questionnaire }\end{array}$} \\
\hline
\end{tabular}

HRQOL. Seven studies estimated the effects of homebased breathing exercises on HRQOL measured with the St George Respiratory Questionnaire. Results indicated that home-based breathing exercises were associ- ated with lower total scores on the St George Respiratory Questionnaire than usual treatment (mean difference $=-8.62,95 \% \mathrm{CI}-13.09$ to $-4.16, P<.001)$ (Fig. 6). 


\section{Home-Based Breathing Exercises in COPD}

\begin{tabular}{|c|c|c|c|c|c|c|c|c|c|c|}
\hline A & & reatmen & & & Contol & & & Mean Difference & Mean D & ifference \\
\hline Study or Subgroup & Mean & SD & Total & Mean & SD & Total & Weight, \% & IV, Fixed, 95\% Cl & IV, Fixed & $\mathrm{d}, 95 \% \mathrm{Cl}$ \\
\hline Gu 2018 & 37.5 & 13.31 & 22 & 36.96 & 12.25 & 20 & 12.5 & $0.54(-7.19$ to 8.27$)$ & & - \\
\hline Hu 2016 & 44.5 & 12.24 & 30 & 39.34 & 9.21 & 30 & 25.0 & $5.16(-0.32$ to 10.64$)$ & & - \\
\hline Kaminsky 2017 & 45 & 14 & 21 & 43 & 13 & 22 & 11.5 & $2.00(-6.08$ to 10.08$)$ & & \\
\hline Lin 2012 & 45.95 & 14.01 & 20 & 52.35 & 18.05 & 20 & 7.5 & $-6.40(-16.41$ to 3.61$)$ & & F \\
\hline Xu 2010 & 59 & 12.6 & 20 & 52.5 & 12.2 & 20 & 12.7 & $6.50(-1.19$ to 14.19$)$ & & \\
\hline Yamaguti 2012 & 42.7 & 39.727 & 15 & 42.7 & 47.311 & 15 & 0.8 & $0.00(-31.26$ to 31.26$)$ & & \\
\hline Zhang 2008 & 38.9 & 7.5 & 17 & 34.5 & 6.9 & 15 & 30.1 & $4.40(-0.59$ to 9.39$)$ & & - \\
\hline Total $(95 \% \mathrm{Cl})$ & & & 145 & & & 142 & 100 & 3.26 (0.52 to 5.99$)$ & & \\
\hline $\begin{array}{l}\text { Heterogeneity: } \mathrm{Chi}^{2} \\
\text { Test for overall effec }\end{array}$ & $\begin{array}{l}=5.53 \\
t: Z=2\end{array}$ & $\begin{array}{l}\mathrm{df}=6(F \\
.33(P=\end{array}$ & $\begin{array}{l}=.48) \\
.02)\end{array}$ & $; I^{2}=0 \%$ & & & & & $\begin{array}{c}-20-10 \\
\text { Favors control }\end{array}$ & $\begin{array}{ccc} & 10 & 20 \\
\text { Favors treatment }\end{array}$ \\
\hline B & & reatmen & & & Contol & & & Mean Difference & Risk & Ratio \\
\hline Study or Subgroup & Mean & SD & Total & Mean & SD & Total & Weight, \% & IV, Fixed, 95\% Cl & M-H, Rand & lom, $95 \% \mathrm{Cl}$ \\
\hline Bonilha 2009 & 47.9 & 21.431 & 15 & 44.5 & 14.151 & 15 & 1.9 & $3.40(-9.60$ to 16.40$)$ & & \\
\hline Li 2013 & 53.2 & 5.4 & 36 & 49.5 & 5.1 & 36 & 55.2 & $3.70(1.27$ to 6.13$)$ & & 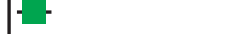 \\
\hline Lin 2012 & 51.62 & 13.15 & 20 & 53.2 & 15.11 & 20 & 4.2 & $-1.58(-10.36$ to 7.20$)$ & & \\
\hline Tang 2016 & 42.36 & 10.34 & 20 & 42.29 & 9.87 & 20 & 8.3 & $0.07(-6.19$ to 6.33$)$ & & - \\
\hline Xu 2010 & 59.3 & 11 & 20 & 52.5 & 10.9 & 20 & 7.1 & $6.80(0.01$ to 13.59$)$ & & \\
\hline Yamaguti 2012 & 39.3 & 26.635 & 15 & 40.8 & 42.436 & 15 & 0.5 & $-1.50(-26.85$ to 23.85$)$ & & \\
\hline Zhang 2008 & 51.2 & 5.8 & 17 & 49.8 & 5.1 & 15 & 22.8 & $1.40(-2.38$ to 5.18$)$ & & - \\
\hline Total $(95 \% \mathrm{Cl})$ & & & 143 & & & 141 & 100 & 2.84 (1.04 to 4.64$)$ & & \\
\hline Test for overall effec & $\mathrm{t}: \mathrm{Z}=3$ & $09(P=$ & $\begin{array}{l}-.05 \\
.002)\end{array}$ & & & & & & $\begin{array}{ll}-20 & -10 \\
\text { Favors control }\end{array}$ & $\begin{array}{lll}0 & 10 & 20 \\
\text { Favors treatment }\end{array}$ \\
\hline
\end{tabular}

Fig. 2. Forest plot depicting the effects of home-based breathing exercises vs usual care on $A$ : percent of predicted FEV $V_{1}$ and $B$ : $\mathrm{FEV}_{1} / \mathrm{FVC}$.

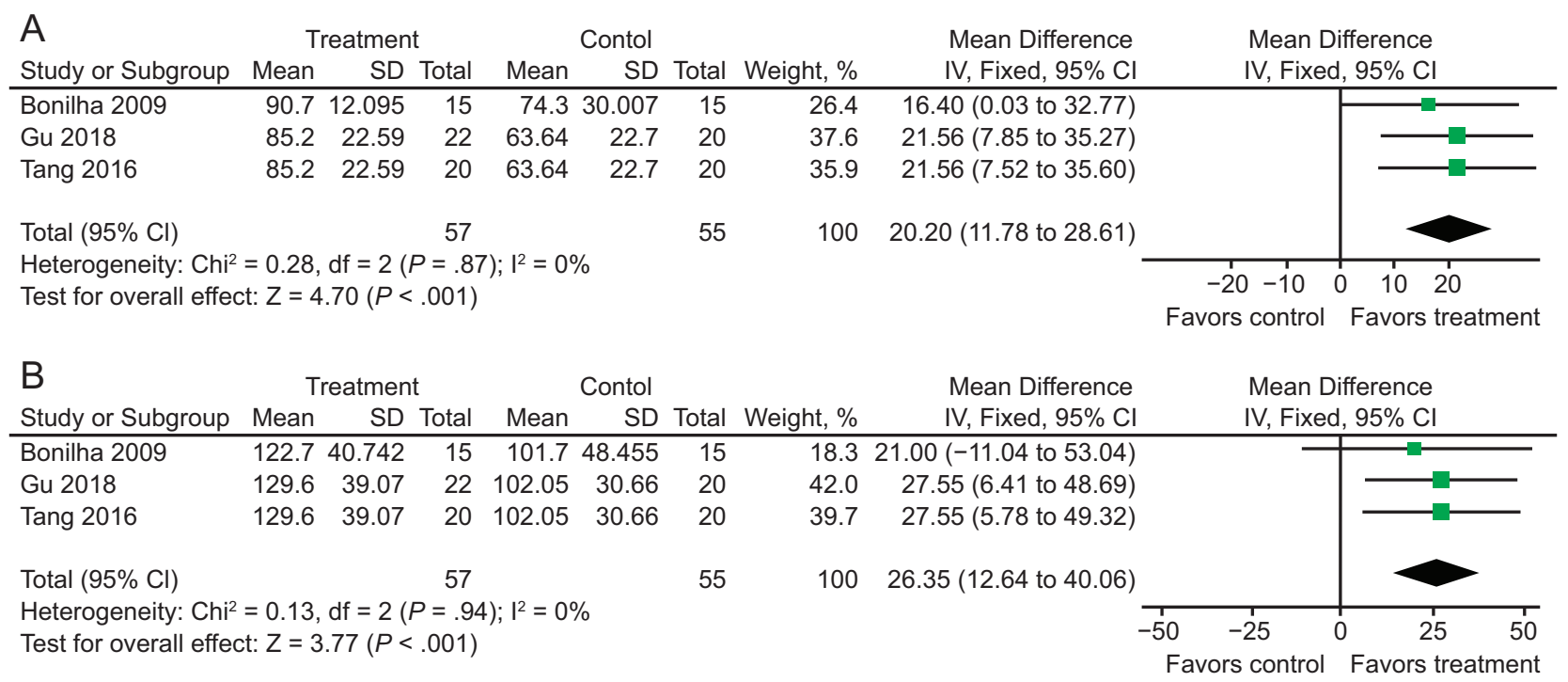

Fig. 3. Forest plot depicting the effects of home-based breathing exercises vs usual care on A: maximum inspiratory pressures and B: maximum expiratory pressures.

\section{Discussion}

Pulmonary rehabilitation is one of the most effective non-pharmacologic treatments for $\mathrm{COPD}^{33}$ and breathing exercises are an important component, ${ }^{34}$ providing an ef- fective method to improve long-term self-efficacy of patients. ${ }^{35}$ However, the methods and effects of breathing exercises are various and still controversial. ${ }^{30}$ Therefore, we conducted a meta-analysis on 13 moderate-to-high quality studies and found significant improvements from home- 


\section{Home-Based Breathing Exercises in COPD}

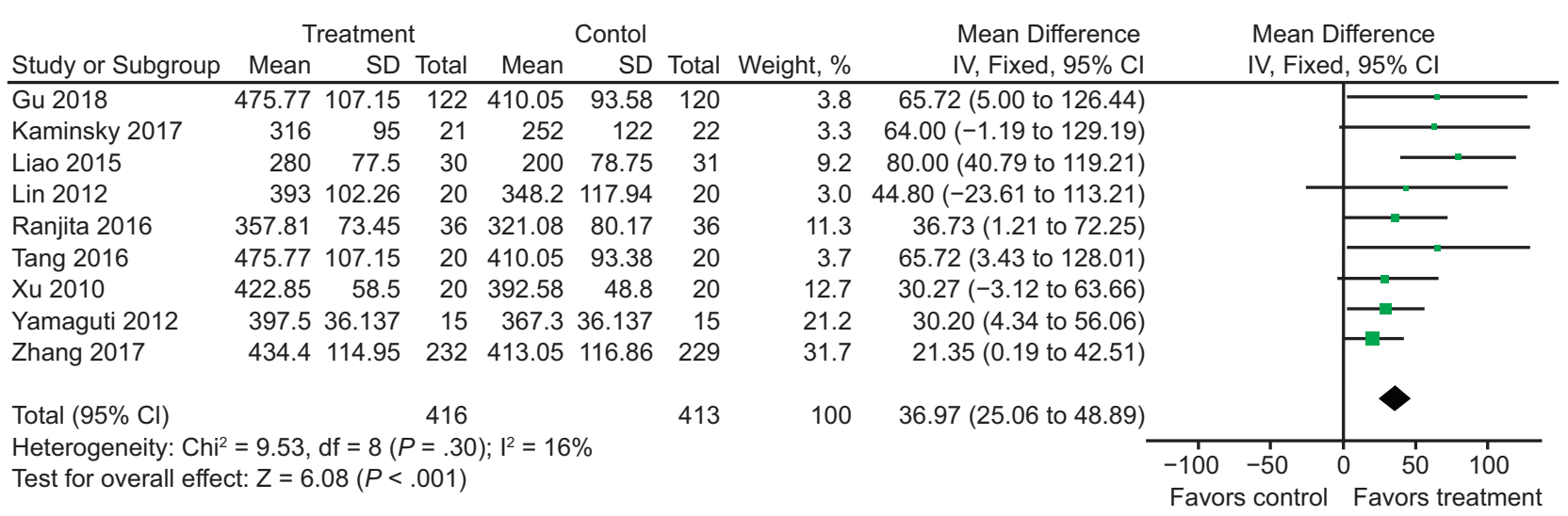

Fig. 4. Forest plot depicting the effects of home-based breathing exercises vs usual care on 6-min walk distance.

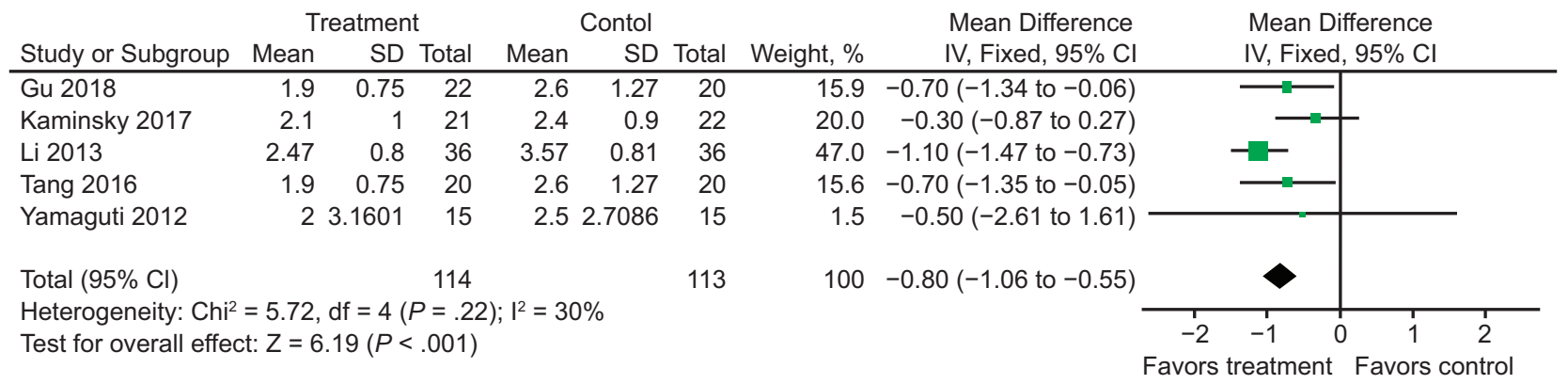

Fig. 5. Forest plot depicting the effects of home-based breathing exercises vs usual care on modified Medical Research Council dyspnea scale.

\begin{tabular}{|c|c|c|c|c|c|c|c|c|c|}
\hline \multirow[b]{2}{*}{ Study or Subgroup } & \multicolumn{3}{|c|}{ Treatment } & \multicolumn{3}{|c|}{ Contol } & \multicolumn{2}{|r|}{ Mean Difference } & \multirow{2}{*}{$\begin{array}{l}\text { Mean Difference } \\
\text { IV, Fixed, } 95 \% \mathrm{Cl}\end{array}$} \\
\hline & Mean & SD & Total & Mean & SD & Total & Weight, \% & IV, Fixed, 95\% Cl & \\
\hline Bonilha 2009 & 30.5 & 12.898 & 15 & 40.7 & 16.769 & 15 & 17.4 & $-10.20(-20.91$ to 0.51$)$ & \\
\hline Gu 2018 & 35.4 & 12.98 & 22 & 47.95 & 18.68 & 20 & 20.7 & $-12.55(-22.37$ to -2.73$)$ & \\
\hline Kaminsky 2017 & 42.2 & 11.6 & 21 & 49.8 & 21.6 & 22 & 18.8 & $-7.60(-17.90$ to 2.70$)$ & \\
\hline Lin 2012 & 41.17 & 28.57 & 20 & 53.33 & 26.02 & 20 & 6.9 & $-12.16(-29.10$ to 4.78$)$ & \\
\hline Lord 2010 & 50 & 15.88 & 15 & 44.9 & 15.88 & 13 & 14.3 & $5.10(-6.69$ to 16.89$)$ & \\
\hline Tang 2016 & 35.4 & 12.98 & 20 & 47.93 & 18.68 & 20 & 20.1 & $-12.53(-22.50$ to -2.56$)$ & \\
\hline Yamaguti 2012 & 43.9 & 47.943 & 15 & 54.8 & 44.061 & 15 & 1.8 & $-10.90(-43.85$ to 22.05$)$ & \\
\hline & & & & & & 125 & 100 & $-8.62(-13.09$ to -4.16$)$ & \\
\hline \multicolumn{9}{|c|}{$\begin{array}{l}\text { Heterogeneity: } \mathrm{Chi}^{2}=6.71, \mathrm{df}=6(P=.35) ; \mathrm{I}^{2}=11 \% \\
\text { Test for overall effect: } \mathrm{Z}=3.79(P<.001)\end{array}$} & 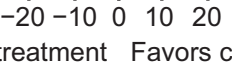 \\
\hline
\end{tabular}

Fig. 6. Forest plot depicting the effects of home-based breathing exercises vs usual care on the St. George Respiratory Questionnaire.

based breathing exercises on pulmonary function, respiratory muscle strength, exercise capacity, dyspnea and HRQOL in patients with COPD.

\section{Effects of Home-Based Breathing Exercises on Pulmonary Function}

Pulmonary function (ie, percent of predicted $\mathrm{FEV}_{1}$ and $\mathrm{FEV}_{1} / \mathrm{FVC}$ ) can effectively reflect the ventilation of patients with COPD and assess the severity of air-flow obstruction. ${ }^{36}$ Quantitative analysis showed a large effect size of home-based breathing exercises on pulmonary function compared to controls. Breathing exercises are a type of aerobic exercise that integrate the mind, body, and spirit and are theoretically based on the dynamic response of the respiratory system. Breathing exercises may alleviate the adverse physiological effects of reduced lung function by enhancing the strength and endurance of the respiratory muscles, optimizing the mechanics of chest and abdominal-wall movement, reducing dynamic hyperinflation, and improving gas exchange. ${ }^{37}$ Home-based breathing exercises can also improve patient adherence to training, which 
ultimately leads to better pulmonary function. A previous study reported that yoga can improve pulmonary function in subjects with COPD by increasing the percent of predicted $\mathrm{FEV}_{1} \cdot{ }^{38}$ Another study noted improved FVC in subjects with COPD after 5 min of pursed-lips breathing, suggesting that pursed-lips breathing may improve pulmonary function by decreasing hyperventilation. ${ }^{39}$ The Global Initiative for COPD (GOLD) recommends a follow-up of at least 12 months for the index of $\mathrm{FEV}_{1}$ in patients with COPD. ${ }^{19}$ However, the duration of studies included in our meta-analysis ranged from 4 to 24 weeks, which is far less than the follow-up time recommended by GOLD. Therefore, it is unclear whether a long-term improvement in pulmonary function can be obtained after home-based breathing exercises. Studies that extended the follow-up time to investigate the long-term effects of breathing exercises on pulmonary function in patients with COPD are recommended. In addition, a study showed that the inspiratory fraction (IF) better reflects lung hyperventilation and exercise capacity in subjects with COPD. ${ }^{40}$ However, it is difficult to analyze the impact of home-based breathing exercises on IF due to the limited use of inspiratory capacity as a primary outcome to reflect IF in patients with COPD.

\section{Effects of Respiratory Training on Respiratory Muscle Strength}

Compared with standard medical treatment, we found that breathing exercises can significantly improve the $\mathrm{P}_{\text {Imax }}$ and $\mathrm{P}_{\text {Emax }}$ of subjects with COPD. Most patients with COPD have weakened respiratory muscles and increased airway resistance, conditions that cause constant overload during breathing and lead to chronic respiratory failure. ${ }^{41}$ Thus, it is vital to enhance the respiratory muscle strength of patients with COPD. Basso-Vanelli et $\mathrm{al}^{42}$ reported that aerobic breathing training can effectively improve the respiratory muscle strength of patients with COPD. In this study, training with singing or a new combined breathing exercise was beneficial in improving respiratory muscle strength in subjects with COPD. The advantage of singing may be related to contraction of abdominal muscles and the diaphragm during training, which improves function. Previous research reported that singing training leads to immediate benefits in vital capacity and respiratory mechanics. ${ }^{43}$ Combined breathing exercises emphasize the combination of inhalation and exhalation, which can effectively enhance the inspiratory-expiratory ratio and reduce breathing frequency. ${ }^{23}$ These findings may be ascribed to structural remodeling of the lateral intercostal muscles after specific breathing training and the increased number of fiber type I and the area of fiber type II. ${ }^{44}$

\section{The Effect of Home-Based Breathing Exercises on Exercise Capacity}

The 6-min walk test is a submaximal exercise test and one of the most widely used methods for assessing exercise capacity in patients with COPD. ${ }^{45}$ The $6 \mathrm{MWD}$ may be a better reflection of the exercise capacity necessary to carry out daily physical activity, because most activities of daily living for patients with COPD are equivalent to moderate exercise levels. Consistent with the results of a study by Holland et al, ${ }^{7}$ Camillo et al ${ }^{46}$ reported that yoga, diaphragmatic breathing, and breathing gymnastics increased 6MWD by an average of $36.94 \mathrm{~m}$ (Fig. 4), which is greater than the minimum clinically important difference (ie, $>30 \mathrm{~m}$ ). These results indicate that home-based breathing exercises produce clinically important improvements in the exercise capacity of patients with COPD. One possible explanation is that breathing training can improve ventilation and increase the patient's daily activities. One study demonstrated that yoga could improve cardiovascular efficiency and steady-state control of breathing, helping to increase walking speed and stride of subjects with COPD, thereby improving functional exercise capacity. ${ }^{11}$

\section{Effects of Home-Based Breathing Exercises on Dyspnea}

Dyspnea is not the primary factor affecting the quality of life of patients with COPD, but it is one of the most clinically important indicators for evaluating the effects of pulmonary rehabilitation. Breathing training can improve effective perfusion of alveoli and reduce hyperinflation by correcting abnormal breathing patterns to further optimize the breathing efficiency and to alleviate dyspnea. ${ }^{47} \mathrm{Al}$ though dyspnea was measured using the mMRC, studies have shown that the 5 grades of this assessment are too broad and insensitive to detect changes in patients with COPD. ${ }^{48}$ Therefore, a variety of measurement methods are recommended for future clinical studies to comprehensively analyze the impact of home-based breathing training on dyspnea in patients with COPD.

\section{Effects of Home-Based Breathing Exercises on HRQOL}

The purpose of COPD treatment is not only to alleviate symptoms, but to improve HRQOL. ${ }^{49}$ Most previous studies have reported that the 3 categories of the St George Respiratory Questionnaire (ie, symptoms, activity, and impact) significantly correlate with HRQOL ${ }^{49,50}$ and is considered the accepted standard of HRQOL assessment. ${ }^{51}$ In this meta-analysis, the pooled effect sizes showed that singing, breathing gymnastics, yoga breathing, and diaphragmatic breathing are beneficial to improve the HRQOL 


\section{Home-Based Breathing Exercises in COPD}

of COPD patients, and the improvement is greater than its minimum clinically important difference (ie, 4 points). One study found that pulmonary rehabilitation has different effects on HRQOL in subjects with varying disease severity. ${ }^{52}$ However, because subjects included in this study were mostly categorized with moderate to very severe COPD, the effects of home-based breathing training on HRQOL across a broad spectrum of COPD severity could not be determined.

\section{Revelation of Home-Based Breathing Exercises}

Pursed-lips breathing can increase expiratory time, decrease breathing frequency, reduce end-expiratory lung volume, increase exercise capacity, and effectively relieve dyspnea. ${ }^{53,54}$ Abdominal breathing focuses on improving breathing pattern, increasing the involvement of the abdominal muscles in breathing, and reducing the activity of the accessory muscles, thereby improving ventilation efficiency and oxygen saturation. ${ }^{55}$ Yoga breathing, as a slow-relaxation breathing training method, can also effectively improve breathing patterns, increase expiratory time, and alleviate static hyperinflation, which has a significant influence on the exercise capacity of patients with COPD. Moreover, studies have shown that yoga breathing can effectively enhance the respiratory muscle strength of subjects with COPD. ${ }^{11}$ Breathing gymnastics improve exercise capacity and HRQOL by integrating and coordinating the patient's breathing, posture, and movement to alleviate the symptoms of dyspnea. The evidence for most physiological benefits is based on traditional Chinese exercise such as tai chi, ba duan jin, and qi gong. Singing training reduces the sensations of anxiety and fear associated with respiratory challenges with its focus on accurate control of breathing. In addition to its possible effects on breathing, singing as a positive experience has been associated with improvements of self-efficacy and HRQOL. ${ }^{56}$ These homebased breathing exercises, although different in training content and specificity, have similar positive effects on alleviating dyspnea and improving exercise capacity in patients with COPD. Studies have reported that breathing exercises combined with exercise training can produce a more significant improvement in breathing frequency compared to breathing exercises alone, thereby more effectively improving lung function, exercise capacity, and dyspnea in patients with COPD. ${ }^{14,57}$ However, future research is necessary due to insufficient information on program type, frequency and duration, and the effects on subjects with different grades of COPD severity.

\section{Limitations}

This study has several limitations. First, this study only searched literature published in Chinese and English; such a limitation on language increases the possibility of missing relevant literature and affects the comprehensiveness of the inclusion. Second, the lack of long-term follow up and large controlled clinical trials make it difficult to draw conclusions on the long-term efficacy of breathing exercises. Third, even though the 13 studies included in this systematic review were of high quality, most studies did not explicitly report allocation concealment, blinding, or intention-to-treat analysis, making assessment of the risk of bias difficult. In addition, one study accounted for nearly half of the overall sample size of our meta-analysis, and only exercise capacity and satisfaction were evaluated in this single study; this is a methodological limitation of our analysis. Fourth, static lung function indicators from subjects with COPD were analyzed in this study instead of comprehensive pulmonary function testing. Fifth, inspiratory muscle training is more effective for patients with COPD with inspiratory muscle weakness. ${ }^{58}$ However, there insufficient data were available from the included studies to complete subgroup analyses to clarify the effects of home-based breathing exercises on subjects with COPD and respiratory muscle weakness. At the same time, this meta-analysis showed that inspiratory muscle training using a threshold device can effectively decrease dyspnea and increase inspiratory muscle strength, quality of life, and exercise capacity, but had no additional effect on dyspnea compared to pulmonary rehabilitation alone. ${ }^{59}$ In this systematic review, we were only able to compare homebased breathing exercises to usual care and were unable to evaluate this training in relation to pulmonary rehabilitation.

\section{Conclusions}

Home-based breathing exercises are beneficial to the pulmonary function, respiratory muscle strength, exercise capacity, dyspnea, and HRQOL of patients with COPD. The characteristics of these exercises, including their ease of execution and lack of constraints on site and time of performance, allow the possibility of their inclusion in a long-term pulmonary rehabilitation program. More attention should be paid to the application of the combined breathing exercise and exercise training program for further benefits.

\section{REFERENCES}

1. Rennard SI, Drummond MB. Early chronic obstructive pulmonary disease: definition, assessment, and prevention. Lancet 2015; 385(9979):1778-1788.

2. Soriano JB, Abajobir AA, Abate KH, Abera SF, Agrawal A, Ahmed $\mathrm{MB}$, et al. Global, regional, and national deaths, prevalence, disability-adjusted life years, and years lived with disability for chronic obstructive pulmonary disease and asthma, 1990-2015: a systematic analysis for the Global Burden of Disease Study 2015. Lancet Respir Med 2017;5(9):691-706. 


\section{Home-Based Breathing Exercises in COPD}

3. Vos T, Abajobir AA, Abate KH, Abbafati C, Abbas KM, Abd-Allah $\mathrm{F}$, et al. Global, regional, and national incidence, prevalence, and years lived with disability for 328 diseases and injuries for 195 countries, 1990-2016: a systematic analysis for the Global Burden of Disease Study 2016. Lancet 2017;390(10100):1211-1259.

4. Corlateanu A, Covantev S, Mathioudakis AG, Botnaru V, Siafakas N. Prevalence and burden of comorbidities in chronic obstructive pulmonary disease. Respir Investig 2016;54(6):387-396.

5. Spruit MA, Singh SJ, Garvey C, ZuWallack R, Nici L, Rochester C, et al. An official American Thoracic Society/European Respiratory Society statement: key concepts and advances in pulmonary rehabilitation. Am J Respir Crit Care Med 2013;188(8):e13-e64.

6. Charususin N, Dacha S, Gosselink R, Decramer M, Von Leupoldt A, Reijnders $\mathrm{T}$, et al. Respiratory muscle function and exercise limitation in patients with chronic obstructive pulmonary disease: a review. Expert Rev Respir Med2018;12(1):67-79.

7. Holland AE, Hill CJ, Jones AY, McDonald CF. Breathing exercises for chronic obstructive pulmonary disease. Cochrane Database Syst Rev 2012(10):CD008250.

8. Borge CR, Hagen KB, Mengshoel AM, Omenaas E, Moum T, Wahl AK. Effects of controlled breathing exercises and respiratory muscle training in people with chronic obstructive pulmonary disease: results from evaluating the quality of evidence in systematic reviews. BMC Pulm Med 2014;14(1):1.

9. Roberts S, Schreuder F, Watson T, Stern M. Do COPD patients taught pursed lips breathing (PLB) for dyspnoea management continue to use the technique long-term? A mixed methodological study. Physiotherapy 2017;103(4):465-470.

10. Mayer AF, Karloh M, dos Santos K, de Araujo CLP, Gulart AA. Effects of acute use of pursed-lips breathing during exercise in patients with COPD: a systematic review and meta-analysis. Physiotherapy 2018;104(1):9-17.

11. Fulambarker A, Farooki B, Kheir F, Copur AS, Srinivasan L, Schultz $\mathrm{S}$. Effect of yoga in chronic obstructive pulmonary disease. Am J Ther 2012;19(2):96-100.

12. Casey M, Mulkerns A, O’Donnell C, McDonnell T. Pulmonary rehabilitation in COPD: current practice and future directions. In: COPD-an update in pathogenesis and clinical management. London: InTechOpen; 2018.

13. Wu W, Liu X, Wang L, Wang Z, Hu J, Yan J. Effects of tai chi on exercise capacity and health-related quality of life in patients with chronic obstructive pulmonary disease: a systematic review and metaanalysis. Int J COPD 2014;9:1253.

14. Mendes LP, Moraes KS, Hoffman M, Vieira DS, Ribeiro-Samora GA, Lage SM, et al. Effects of diaphragmatic breathing with and without pursed-lips breathing in subjects with COPD. Respir Care 2019;64(2):136-144.

15. Yamaguti WP, Claudino RC, Neto AP, Chammas MC, Gomes AC, Salge JM, et al. Diaphragmatic breathing training program improves abdominal motion during natural breathing in patients with chronic obstructive pulmonary disease: a randomized controlled trial. Arch Phys Med Rehabil 2012;93(4):571-577.

16. Bhatt SP, Luqman-Arafath T, Gupta AK, Mohan A, Stoltzfus JC, Dey $\mathrm{T}$, et al. Volitional pursed lips breathing in patients with stable chronic obstructive pulmonary disease improves exercise capacity. Chron Respir Dis 2013;10(1):5-10.

17. Collins EG, Jelinek C, O’Connell S, Butler J, Reda D, Laghi F. The effect of breathing retraining using metronome-based acoustic feedback on exercise endurance in COPD: a randomized trial. Lung 2019;1-8.

18. Moher D, Liberati A, Tetzlaff J, Altman DG, Group P. Preferred reporting items for systematic reviews and meta-analyses: the PRISMA statement. PLoS Med 2009;6(7):e1000097.
19. Mirza S, Clay RD, Koslow MA, Scanlon PD. COPD guidelines: a review of the 2018 GOLD report. Mayo Clin Proc 2018;93(10): 1488-1502.

20. Moseley AM, Herbert RD, Sherrington C, Maher CG. Evidence for physiotherapy practice: a survey of the Physiotherapy Evidence Database (PEDro). Aust J Physiother 2002;48(1):43-49.

21. Kaminsky DA, Guntupalli KK, Lippmann J, Burns SM, Brock MA, Skelly J, et al. Effect of yoga breathing (pranayama) on exercise tolerance in patients with chronic obstructive pulmonary disease: a randomized, controlled trial. J Altern Complement Med 2017;23(9): 696-704.

22. Zhang HL, Li JS, Yu XQ, Li SY, Halmurat U, Xie Y, et al. An evaluation of activity tolerance, patient-reported outcomes and satisfaction with the effectiveness of pulmonary daoyin on patients with chronic obstructive pulmonary disease. Int J COPD 2017;12:23332342.

23. Tang W, Wang M, Lin W. The clinical applying study of a novel breathing training manoeuvre in patients with COPD. Int J Respir 2016;36(19):1458-1461.

24. Hu Y, Zhang W. Study on traditional Chinese medicine respiratory guidance and rehabilitation technology improving lung function of COPD patients. Chinese Archives of Traditional Chinese Medicine, 2016;34(02):414-417. (in Chinese)

25. Ranjita R, Hankey A, Nagendra H, Mohanty S. Yoga-based pulmonary rehabilitation for the management of dyspnea in coal miners with chronic obstructive pulmonary disease: a randomized controlled trial. J Ayurveda Integr Med 2016;7(3):158-166.

26. Li FQ. Effect of respiratory function training on lung function and quality of life in patients with COPD remission. Nursing Pract Res 2013;10(20):8-9.

27. Lin WC, Yuan SC, Chien JY, Weng SC, Chou MC, Kuo HW. The effects of respiratory training for chronic obstructive pulmonary disease patients: a randomised clinical trial. J Clin Nurs 2012;21(19pt20): 2870-2878.

28. Xu Y, Wang J, Li H, Zhu X, Wang G. Efficacy of integrative respiratory rehabilitation training in exercise ability and quality of life of patients with chronic obstructive pulmonary disease in stable phase: a randomized controlled trial. Zhong Xi Yi Jie He Xue Bao 2010;8(5):432-437.

29. Lord VM, Cave P, Hume VJ, Flude EJ, Evans A, Kelly JL, et al. Singing teaching as a therapy for chronic respiratory disease-a randomised controlled trial and qualitative evaluation. BMC Pulm Med 2010;10(1):41.

30. Gu WL, Liang ZY, Zhu CB, Chen RC. Clinical outcome of a novel breathing training maneuver in stable COPD patients. Int $\mathrm{J}$ Clin Exper Med 2018;11(9):9802-9810.

31. Bonilha AG, Onofre F, Vieira ML, Prado MYA, Martinez JAB. Effects of singing classes on pulmonary function and quality of life of COPD patients. Int J COPD 2009;4:1-8.

32. Zhang ZQ, Chen RC, Yang QQ, Li P, Wang CZ, Zhang ZH. The clinical study of pulmonary rehabilitation toward expiratory airflow limitation of COPD. Chinese J Rehabil Med 2008;23(6):499-504.

33. Gloeckl R, Marinov B, Pitta F. Practical recommendations for exercise training in patients with COPD. Eur Respir Rev 2013;22:178186.

34. Gosselink R. Breathing techniques in patients with chronic obstructive pulmonary disease (COPD). Chron Respir Dis 2004;1(3):163172 .

35. Effing TW, Bourbeau J, Vercoulen J, Apter AJ, Coultas D, Meek P, et al. Self-management programmes for COPD: moving forward. Chron Respir Dis 2012;9(1):27-35.

36. Vogelmeier CF, Criner GJ, Martinez FJ, Anzueto A, Barnes PJ, Bourbeau J, et al. Global strategy for the diagnosis, management, and prevention of chronic obstructive lung disease 2017 report. GOLD 


\section{Home-Based BReathing Exercises in COPD}

executive summary. Am J Respir Crit Care Med 2017;195(5):557582.

37. Hanania NA, O'Donnell DE. Activity-related dyspnea in chronic obstructive pulmonary disease: physical and psychological consequences, unmet needs, and future directions. Int J COPD 2019;14: 1127.

38. Liu XC, Pan L, Hu Q, Dong WP, Yan JH, Dong L. Effects of yoga training in patients with chronic obstructive pulmonary disease: a systematic review and meta-analysis. J Thorac Dis 2014;6(6):795.

39. Visser FJ, Ramlal S, Dekhuijzen PN, Heijdra YF. Pursed-lips breathing improves inspiratory capacity in chronic obstructive pulmonary disease. Respiration 2011;81(5):372-378.

40. Zhang Y, Sun XG, Yang WL, Tan XY, Liu JM. Inspiratory fraction correlates with exercise capacity in patients with stable moderate to severe COPD. Respir Care 2013;58(11):1923-1930.

41. Barreiro E, Gea J. Respiratory and limb muscle dysfunction in COPD. COPD 2015;12(4):413-426.

42. Basso-Vanelli RP, Di Lorenzo VAP, Labadessa IG, Regueiro EM, Jamami M, Gomes EL, et al. Effects of inspiratory muscle training and calisthenics-and-breathing exercises in COPD with and without respiratory muscle weakness. Respir Care 2016;61(1):50-60.

43. Skingley A, Page S, Clift S, Morrison I, Coulton S, Treadwell P, et al. Singing for breathing: participants' perceptions of a group singing programme for people with COPD. Arts Health 2014;6(1):59-74.

44. Gea J, Agustí A, Roca J. Pathophysiology of muscle dysfunction in COPD. J Appl Physiol 2013;114(9):1222-1234.

45. Spruit MA, Watkins ML, Edwards LD, Vestbo J, Calverley PM, Pinto-Plata V, et al. Determinants of poor 6-min walking distance in patients with COPD: the ECLIPSE cohort. Respir Med 2010;104(6): 849-857.

46. Camillo CA, Langer D, Osadnik CR, Pancini L, Demeyer H, Burtin C, et al. Survival after pulmonary rehabilitation in patients with COPD: impact of functional exercise capacity and its changes. Int $\mathrm{J}$ COPD 2016;11:2671.

47. Gosselink R. Controlled breathing and dyspnea in patients with chronic obstructive pulmonary disease (COPD). J Rehabil Res Dev 2003;40(5 Suppl 2):25-34.

48. Oga T, Tsukino M, Hajiro T, Ikeda A, Nishimura K. Analysis of longitudinal changes in dyspnea of patients with chronic obstructive pulmonary disease: an observational study. Respiratory Res 2012; 13:85.

49. Pickard AS, Yang Y, Lee TA. Comparison of health-related quality of life measures in chronic obstructive pulmonary disease. Health Qual Life Outcomes 2011;9(1):26.

50. Nonato NL, Díaz O, Nascimento OA, Dreyse J, Jardim JR, Lisboa C. Behavior of quality of life (SGRQ) in COPD patients according to BODE scores. Arch Bronconeumol 2015;51(7):315-321.

51. Folch Ayora A, Macia-Soler L, Orts-Cortés MI, Hernández C, Seijas-Babot N. Comparative analysis of the psychometric parameters of two quality-of-life questionnaires, the SGRQ and CAT, in the assessment of patients with COPD exacerbations during hospitalization: a multicenter study. Chron Respir Dis 2018;15(4):374-383.

52. Bratås O, Espnes G, Rannestad T, Walstad R. Pulmonary rehabilitation reduces depression and enhances health-related quality of life in COPD patients-especially in patients with mild or moderate disease. Chron Respir Dis 2010;7(4):229-237.

53. Spahija J, de Marchie M, Grassino A. Effects of imposed pursed-lips breathing on respiratory mechanics and dyspnea at rest and during exercise in COPD. Chest 2005;128(2):640-650.

54. Bhatt SP, Luqman-Arafath TK, Gupta AK, Mohan A, Stoltzfus JC, Dey $\mathrm{T}$, et al. Volitional pursed lips breathing in patients with stable chronic obstructive pulmonary disease improves exercise capacity. Chron Respir Dis 2013;10(1):5-10.

55. Fernandes M, Cukier A, Feltrim MIZ. Efficacy of diaphragmatic breathing in patients with chronic obstructive pulmonary disease. Chron Respir Dis 2011;8(4):237-244.

56. Grasch A, Colle J, Todd S, Hazelrigg S. Daily singing practice as a means of improving pulmonary function and quality of life in emphysema patients. Cureus 2013;5(3):e103

57. Al Karn AF, Hassan WA, El Fadl AAA, Mahmoud MA. Effectiveness of pulmonary rehabilitation on pulmonary function parameters and dyspnea in patients with stable chronic obstructive pulmonary disease. Egypt J Bronchol 2018;12(2):149.

58. Gosselink R, De Vos J, Van Den Heuvel S, Segers J, Decramer M, Kwakkel G. Impact of inspiratory muscle training in patients with COPD: what is the evidence? Eur Respir J 2011;37(2):416-425.

59. Beaumont M, Forget P, Couturaud F, Reychler G. Effects of inspiratory muscle training in COPD patients: a systematic review and meta-analysis. Clin Respir J 2018;12(7):2178-2188. 